\title{
METROPOLIZAÇÃO DO ESPAÇO, GESTÃO TERRITORIAL E RELAÇÕES URBANO-RURAIS: ALGUMAS INTERAÇÕES POSSÍVEIS
}

\author{
METROPOLIZATION OF SPACE, TERRITORIAL MANAGEMENT AND \\ URBAN-RURAL RELATIONSHIPS: POSSIBLE INTERACTIONS
}

\author{
Alvaro Ferreira \\ Departamento de Geografia e Meio Ambiente da PUC-Rio \\ e do Departamento de Geografia da UERJ-FEBF \\ alvaro_ferreira@puc-rio.br \\ João Rua \\ Departamento de Geografia e Meio Ambiente da PUC-Rio \\ joaorua@uol.com.br \\ Regina Célia de Mattos \\ Departamento de Geografia e Meio Ambiente da PUC-Rio \\ rcm@puc-rio.br
}

\begin{abstract}
RESUMO
O artigo desenvolve a hipótese de acordo com a qual a reprodução do espaço, no mundo contemporâneo, aprofunda a contradição entre o processo de produção social do espaço e sua apropriação privada. A metropolização do espaço, num sentido amplo, contribui para transformar as dinâmicas espaciais urbano-metropolitanas em todas as escalas territoriais. O espaço é um produto social e é produzido com intenções que interferem na vida cotidiana. O planejamento e a gestão territorial num momento de agudização das contradições sociais e de práticas excludentes, em todas as escalas geográficas, são definidos na relação com os direitos coletivos e individuais. Em outras palavras, eles operam na presunção de que, por um lado, existe a lógica territorial dos grupos sociais afetados/dominados pelas geometrias de poder, por outro lado, está a lógica dos que gerenciam os projetos de desenvolvimento. A recente corrida global por terra produziu um dramático implemento dos investimentos na compra de terras no Brasil. A tendência atual acentua os processos em curso de elevação dos preços da terra bem como as consequências desses processos. O trabalho enfoca as interações entre a gestão territorial e as relações urbano-rurais integrados pela metropolização do espaço vista como o processo espacial dominante nos dias atuais.
\end{abstract}

Palavras-chave: metropolização do espaço - gestão territorial - relações urbano-rurais - desenvolvimentos geograficamente desiguais

\footnotetext{
ABSTRACT

The article develops the hypothesis according to which the reproduction of the space, in the contemporary world, deepens the contradiction between the social production process of space and its private appropriation. The metropolization of space, in a broad 
sense, contributes to transform urban/metropolitan spatial dynamics in every territorial scale. Space is a social product and is produced with intentions that interfere in everyday life. The planning and territorial management in a moment of sharpening of social contradictions and exclusionary practices in all geographical scales are defined in relation to collective and individual rights. In other words, they operate with the assumption that there is, on the one hand, the territorial logic of social groups affected/dominated by the power-geometries and, on the other side, is the logic of those who manage development projects. The recent global rush for farmland has produced a dramatic increase in investments in land in Brazil. The current trend accentuates the ongoing process of increasing land prices as well as the consequences of this process. The paper focuses the interactions between territorial management and urban-rural relationships integrated by the metropolization of space seen as the dominant spatial process nowadays.

Keywords: metropolization of space - territorial management - urban-rural relationships - uneven geographical developments

Ao se falar em metropolização do espaço deve-se, de imediato, remeter-se a alguns fatos que darão sentido à análise a ser efetuada. O primeiro é a consideração de que o fenômeno urbano, ligado à industrialização e à aglomeração (complexos urbanoindustriais), marca das décadas anteriores à atual, vem dando lugar ao fenômeno metropolitano, ligado à desindustrialização e às transformações na organização do trabalho propiciando o aumento de sua precarização, não entendido aqui o trabalho apenas como a força de trabalho enquanto mercadoria, mas do homem que trabalha em um contexto histórico concreto do capitalismo manipulatório (Alves, 2011), à desconcentração e à "explosão" da metrópole, isto é, à difusão dos códigos metropolitanos, num sentido amplo dessa imagem, num espaço muito além dos limites das regiões metropolitanas, oficialmente delimitadas.O segundo fato refere-se à consideração de que diversos outros processos espaciais estarão afetados por essa transformação de urbano para urbano-metropolitano ou, simplesmente, metropolitano. Especificamente estarão sendo referidos a gestão territorial e as relações urbano-rurais processos percebidos como fortemente marcados pela metropolização do espaço, processos alterados pela dinâmica metabólica entre os espaço-tempo de vida e espaçotempo de trabalho (MÉSZÁROS, 2002).

O objetivo deste artigo é mostrar a relação entre esses três processos numa perspectiva multiescalar em que o primeiro subsume os dois outros, não só por alcançar a escala geral do território, mas, principalmente, por atribuir-lhes propriedades que, até recentemente, não possuíam ou eram fracamente manifestadas. Essas manifestações 
podem ser percebidas nas novas formas de gestão em que o lugar e as chamadas intervenções localizadas (e em parcerias público-privadas) ganham ênfase, em detrimento de intervenções mais centralizadas, com um papel mais direcionador do poder público; ao mesmo tempo a antiga dicotomia rural-urbano, característica de divisões de trabalho anteriores à atual, é substituída por uma espacialidade híbrida, em que a dimensão metropolitana está presente no rural, alterando-o, principalmente nos comportamentos, fruto daquela difusão dos códigos metropolitanos que conjugam novas experiências humanas em um contexto histórico-concreto: o capitalismo financeiro contemporâneo.

Assim, a gestão territorial e as relações urbano-rurais serão compreendidas como processos integrados àquela escala mais geral de análise. O Estado do Rio de Janeiro servirá como exemplo de cada processo em cada escala observada.

\section{Metropolização do espaço: alterações profundas na lógica e na dinâmica de produção do espaço}

A metropolização marca o momento atual da organização do espaço e das práticas espaciais que nele se realizam, como já dito. Contribui, assim, para a realização de profundas transformações das formas, estrutura e dinâmicas espaciais ao superar a urbanização, marca de uma "geografia" anterior à atual (ou às atuais).

Pode-se dizer que a metropolização incorpora algumas características anteriores e desenvolve outras. Trata-se, por exemplo, como lembra Sandra Lencioni, da grande intensidade de fluxos de pessoas, mercadorias e capitais, do crescimento das atividades de serviços e de cada vez maior demanda do trabalho imaterial, da concentração de atividades de gestão e administração, da cada vez maior utilização de tecnologias de informação e comunicação, de grande variedade de atividades econômicas com maior concentração de serviços de ordem superior, da exacerbação da associação entre o capital financeiro, promotores imobiliários e da indústria da construção, da produção de um modo de viver e de consumo que se espelha no perfil da metrópole (LENCIONI, 2013, 2006; FERREIRA, 2014, 2013a, 2011 e RUA, 2013).Às relações formais e salariais, o desenvolvimento desigual articula ao processo geral de acumulação formas precárias, e grande parte informal de trabalho. 
Assim a metropolização do espaço não se restringe às regiões metropolitanas, já que incorpora as cidades médias, as pequenas e o chamado "mundo" rural, hoje muito transformado e incorporando urbanidades. A isso se retornará mais adiante.

Atualmente, experimenta-se um momento do urbano que já não é mais tão marcado pelas lógicas espaciais da indústria, algo que provoca transformações nas cidades e no campo, pois o predomínio de uma economia baseada nesse setor produtivo abriu lugar àquela mais ligada aos serviços. Se cada vez mais é comum ouvir-se falar em desindustrialização, isso não significa dizer que a indústria se afasta daquilo que chamamos de urbano, que, nos dias atuais, deixou de ser sinônimo de cidade. O urbano está ligado à condição geral do processo de reprodução do capital, sendo simultaneamente produto desse processo que transformou o trabalho útil, sua dimensão concreta, ponto de partida da sociabilidade humana, em trabalho abstrato, isto é, em mercadoria, cuja finalidade é valorizar o capital.

A dinâmica do processo de metropolização tem contribuído para a transformação do mercado do solo urbano, que passa por intensa valorização elevando os preços a números nunca antes imaginados. Percebe-se, então, a importância da propriedade privada do solo como "condição indispensável à produção imobiliária formal", como lembra Lencioni (2013, p. 29). Tal elevação de preços faz com que as construtoras busquem áreas mais distantes para construção, incorporando novas áreas à lógica de mercado da metrópole; fato que obriga os moradores a realizarem grandes deslocamentos diariamente. Isso acaba por estender a área urbana indefinidamente, comprometendo inclusive o rural, integrado, cada vez mais a esse processo especulativo, como se verá. Para falar desse espraiamento exacerbado da malha urbana inúmeros autores passaram a referir-se à cidade difusa, cidade dispersa ${ }^{\mathrm{i}}$, cidaderegião ${ }^{\mathrm{iii}}$, cidade ilimitada ${ }^{\mathrm{iv}}$, mega-cidade $^{\mathrm{v}}$, hiper-cidade $^{\mathrm{vi}}$ etc.

A dispersão a que nos referimos tem evidentemente elementos de continuidade, que tem várias raízes, dentre elas, como afirma Capel (2003, p. 212), os processos de descentralização que se iniciaram no século XIX, reforçados por inovações técnicas (ferrovia, telégrafo, telefone, bondes, ônibus) que permitiam a localização periférica de atividades que antes se situavam no centro urbano. Outro fator que contribuiu para o espraiamento da malha urbana, como mencionado anteriormente, foi o aumento do 
preço do solo e da habitação nas áreas consolidadas. As construtoras, associadas aos promotores imobiliários, investem na compra de terras em áreas mais afastadas, consolidando uma espécie de carteira ou um banco de terra. Isso dá a seus proprietários o monopólio da área de expansão da cidade.

As áreas de expansão e de investimentos nas cidades (e, já agora, também em algumas áreas do campo) acabam sendo definidas pelos proprietários fundiários, pelas construtoras e pelos promotores imobiliários. O processo de metropolização tem, simultaneamente, levado ao adensamento de determinadas áreas, ao espraiamento da metrópole e às operações urbanas de renovação ou de revitalizações (como preferem alguns), que acabam por gerar forte gentrificação. Vivencia-se uma transformação que incorpora as dimensões econômica e social, em que grandes investimentos da esfera pública viabilizam a criação e/ou expansão das áreas centrais, articuladas à reprodução do capital financeiro, que produz segregação e apropriação desigual do espaço urbano, gerando (ou propiciando uma):

... tendência para a especialização geográfica na reprodução social (que) pode assumir uma forma ainda mais enfática. Os processosde reprodução social então se cristalizam em uma colcha de retalhos relativamente permanente de especialização local, inter-regional e até internacional. Essa colcha de retalhos pode então ser associada a diferenciais marcantes no valor e na produtividade da força de trabalho (HARVEY, 2013, p. 489).

No início do século XXI, percebe-se que cada vez mais os governantes procuram construir uma marca para suas cidades; contudo o "sucesso" de uma determinada cidade acaba provocando um movimento que objetiva copiar aquilo que teria dado certo, levando à homogeneização das formas-conteúdo, pois acreditam que assim atrairiam investidores. Contradição que aponta para uma espécie de urbanização banalizada e consequentemente para a banalização do espaço (FERREIRA, 2013b).

Tem-se, simultaneamente, um discurso que defende a manutenção dos centros históricos - vislumbrando o potencial de exploração turística dessas áreas - e o crescimento do número de condomínios fechados e shopping centers. Os velhos centros muitas vezes não são vistos como opção para habitação, mas como possibilidade para o crescimento de atividades comerciais.

Muitas cidades têm seguido as definições de uma política empreendedorista, investindo em infraestrutura ligada às atividades turísticas, muitas vezes aproveitando- 
se de eventos internacionais como o fizeram Barcelona (Jogos Olímpicos, 1992 e o Fórum de las Culturas, 2004), Lisboa (Expo'98) ou Sevilha (Expo'92); o Rio de Janeiro vem seguindo o mesmo caminho: Jogos Pan-Americanos 2007, Copa do Mundo de Futebol 2014, Olimpíadas 2016.

Assim, agências multilaterais - BID, Banco Mundial, PNUD, Agência Habitat, dentre outras - e consultores internacionais acabam construindo ideários e modelos que afirmam que as cidades devem comportar-se como empresas e adotar uma postura vencedora em um mundo que é visto como um mercado em que cidades competem entre si (VAINER, 2000). Dessa forma, esse ideário defende que grandes projetos urbanos, recuperação de centros históricos, parcerias público-privadas e revitalizações fomentam a produtividade e competitividade da cidade, assegurando - graças à atração de investimentos, turistas e grandes eventos - uma inserção de sucesso no mundo globalizado. Além disso, surgem também como opção a criação de parques associados a grandes projetos imobiliários de condomínios de alto poder aquisitivo. A parte do tecido urbano avaliada pelos empreendedores como degradada ou habitada por grupos sociais de baixo poder aquisitivo, como velhas áreas fabris e armazéns em antigas zonas portuárias, tornam-se áreas potenciais para passar por refuncionalizações e para se transformarem em novos complexos de consumo. Nesse sentido, todo lugar acaba tornando-se uma cópia, em que surgem paisagens urbanas cada vez mais repetitivas que se descolam da própria realidade e história do lugar; é isso que se caracteriza como uma espécie de urbanização banalizada.

Grande parte dos projetos de revitalização, que alteram as características do lugar criando novas fronteiras urbanas, acaba levando a processos de gentrificação, que de certa forma não deixa de ser uma forma de espoliação (FERREIRA, 2013b).

Acredita-se que a espetacularização na administração pública e a pura valorização da imagem, e não da essência dos problemas sociais e econômicos, acaba sendo extremamente prejudicial em longo prazo, ainda que, muitas vezes, no curto prazo possam ser obtidos benefícios políticos.

A cidade é a materialização de um momento histórico. O espaço torna-se cada vez mais o meio de reprodução das relações sociais; sendo hierarquizado, objeto de investimentos públicos e privados, e também reserva de valor. Talvez a grande batalha deva centrar-se na necessidade de romper com a ocultaçãoda reificação das práticas 
sociais e buscar desvelar essa dominação do espaço. No atual momento do capitalismo mundial, o movimento da reprodução aponta para a superação da hegemonia do capital industrial pelo capital financeiro, levando ao acirramento do processo de produção desigual do espaço (FERREIRA, 2014).

Experimenta-se um momento marcado pela desconcentração do setor produtivo tradicional, pelo desenvolvimento de novos ramos da economia e pela centralização do capital na metrópole (LENCIONI, 1991). Além disso, observamos a conformação de uma cidade difusa, que se expande desmesuradamente, dando novos conteúdos às antigas áreas rurais (adiante trataremos disso com mais detalhes).

O espaço é o lugar da reprodução das relações sociais de produção e não apenas dos meios de produção, destarte percebemos o espaço como mercadoria. Porém, se o espaço é o lugar da reprodução, é também lugar da contestação, do encontro, da rebeldia, lugar da ação. E aqui se está diante de grandes tensões, contradições; ou seja, se é no espaço da vida cotidiana que se percebe e se vive o dia-a-dia, é nele também que os especialistas - cientes ou não do fato de que o espaço produzido interfere fortemente nas relações sociais - concebem seus projetos e os põem em curso, na maioria das vezes, à revelia dos habitantes do lugar, que alienados, vivem uma vida reificada. Muitas vezes, aqueles que vivem na cidade acabam por perceber e viver a partir da total naturalização de tudo, da banalização da miséria, da desigualdade. Por outro lado, há também aqueles atores sociais que, a partir da indignação, procuram formas de lutar contra o estado de coisas atual; as estratégias de suas práticas espaciais são fundamentais, posto que percebem que a produção do espaço é também instrumento de reprodução das relações sociais.

O cotidiano, embora muitas vezes banalizado, já que se expressa por sua miséria e riqueza a partir de eventos triviais, caracteriza-se como a mediação entre a repetição e a criação, entre a alienação e a liberdade, como a clara explicitação da imbricação entre espaço e tempo. As inúmeras possibilidades de apropriação do cotidiano resultam da vivência, da experiência vivida, e tem grande potencial criador, possibilitando a formação e permanência de resistências. Portanto, quando através da apropriação do espaço da cidade se reconstrói a cotidianidade, é possível pensar na formação de movimentos que lutem pela emancipação e pela sua transformação, apontando para uma 
forma de gestão que priorize a participação popular de maneira intensa (posteriormente procurar-se-á fazer alguns apontamentos nessa direção).

Retomando, é possível afirmar que o processo de metropolização imprime características metropolitanas ao espaço, trata-se da alteração das estruturas préexistentes, sendo esses espaços metrópoles ou não; ou seja, trata-se da transcendência das características metropolitalinas a todo o espaço. Se o fenômeno urbano tomou o planeta, se se vive uma sociedade urbana (e não se refere aqui apenas ao domínio edificado), atualmente experimenta-se um processo de metropolização do espaço (FERREIRA, 2014, 2011).

Há, também, a incorporação de uma dimensão cultural. A esfera do consumo ganha proporções antes desconhecidas, provocando uma alteração profunda da cultura mercantil, que atinge todas as esferas da vida. Os hábitos culturais e os valores urbanos típicos da metrópole se difundem para além dela, chegando a todo o espaço, territorializado na mercadificação generalizada.

A intensificação da capitalização do campo e a diversificação das atividades que lá se realizam, associadas ao desenvolvimento das tecnologias de comunicação e informação, e também dos transportes aproximaram ainda mais as relações urbano-rurais. Assim, o processo de metropolização do espaço chega a áreas cada vez mais distantes, difundindo a cultura urbana, os valores urbanos, as normas e práticas sociais dominantes da metrópole. Se em determinado momento pudemos falar em urbanidades no rural, talvez agora tenhamos de aprofundar ainda mais esse debate, já que, atualmente, objetiva-se o desenvolvimento de condições metropolitanas que viabilizem ainda mais a reprodução do capital, a expansão do trabalho abstrato.

Não resta dúvida de que as estratégias de gestão territorial são, como vimos, também atingidas por tal processo. Ao discuti-lo, pensa-se em políticas públicas, bastante questionadas em sua concepção, execução e seus resultados; pensa-se em outras formas de gestão e planejamento; pensa-se em como viabilizar formas de autogestão.

\section{Gestão territorial: reunindo olhares aparentemente contraditórios}

Ao falar de território lida-se com, pelo menos, duas dimensões analíticas, ainda bastante separadas. A primeira, bastante formal, e tradicional na Geografia, refere-se Geo UERJ. Rio de Janeiro - Ano 16, nº. 25, v.2, $2^{\circ}$ semestre de 2014, pp.477-504

ISSN: 1415-7543 E-ISSN: 1981-9021

http://www.e-publicacoes.uerj.br/index.php/geouerj 
mais à dimensão político-administrativa e aos distintos níveis do poder oficial; a segunda, mais simbólica, relaciona-se com outras formas de exercício do poder, não oficial (muitas vezes a ele se contrapondo) e se realizando nos interstícios daquele primeiro. Haesbaert (1997, p. 42), para conceituar território, escreveu que:

O território envolve sempre, ao mesmo tempo, mas em diferentes graus de correspondência e intensidade, uma dimensão simbólica, cultural, através de uma identidade territorial atribuída pelos grupos sociais, como forma de "controle simbólico" sobre o espaço onde vivem (sendo também, portanto, uma forma de apropriação), e uma dimensão mais concreta, de caráter político-disciplinar: a apropriação e ordenação do espaço como forma de domínio e disciplinarização dos indivíduos.

Haesbaert, assim, remete-se às dimensões variadas que compõem esse conceito. A dimensão simbólico-cultural, em que o território é visto, sobretudo, como produto da apropriação/valorização simbólica de um grupo sobre seu espaço, e onde os geosímbolos que definem uma paisagem cultural marcam a inscrição da cultura desse grupo sobre o espaço, tem sido pouco capturada pelos atores hegemônicos na elaboração de políticas de gestão, mesmo que se fale de "participação popular", ela é pouco definidora das ações encetadas. A segunda dimensão, a jurídico-política, é a mais difundida entre os gestores e planejadores. Nela, o território é visto como um espaço delimitado e controlado, através do qual se exerce um determinado poder, na maioria das vezes visto como o poder político do Estado.

Adota-se essa clássica definição do autor supracitado como base para as (breves) discussões sobre gestão, porque ela vai iluminar as argumentações que vão contrapor e complementar visões que, até o momento, parecem antagônicas.

Muito marcado pelo pensamento de Lefebvre, em Haesbaert (1995, p. 35 e 2005, p. 6774), pode-se ver o destaque da interação entre dominação (de caráter mais funcionalinstrumental) e apropriação (de caráter mais simbólico ou do espaço vivido), em que o primeiro refere-se a um processo mais concreto, funcional e vinculado ao valor de troca, enquanto o segundo seria muito mais simbólico, carregado das marcas do "vivido", do valor de uso.

O que se apresenta como pressuposto básico é que há uma dimensão territorial oficial, afetada pelas diversas crises que marcam o momento atual do estado capitalista do neoliberalismo, incluindo as crises de governança, que convive com outras dimensões do território (simbólico-culturais), ora a elas se opondo como na repressão a

Geo UERJ. Rio de Janeiro - Ano 16, no. 25, v.2, $2^{\circ}$ semestre de 2014, pp.477-504

ISSN: 1415-7543 E-ISSN: 1981-9021

http://www.e-publicacoes.uerj.br/index.php/geouerj 
diversas manifestações dos movimentos sociais, ora reconhecendo-as como em algumas reivindicações quilombolas, seringueiras, do MST etc.

Seguindo Haesbaert (2011, p. 30) é preciso considerar, nesse papel desreterritorializador do Estado, diversos elementos, como, por exemplo, os sujeitos em jogo e seus objetivos políticos, desde os grupos hegemônicos (político-militares e econômicos), em suas reestruturações conservadoras, até os movimentos sociais de resistência em suas estratégias de transformação autonomista; as escalas da reestruturação de ação interna e externa do Estado; os níveis de flexibilização e/ou centralização das decisões nas mãos do aparato estatal e suas repercussões diferenciadas.

Como visto acima, o Estado participa ativamente (e retoma gradativamente essa participação) das territorializações localizadoras das empresas, por exemplo na esfera municipal ou estadual, ao oferecer vantagens competitivas para investimentos privados, ou a eles se associando em parcerias público-privadas. Incluem-se aí, as escalas internas e externas da ação oficial. As repercussões diferenciadas têm relação direta com a capacidade de influência dos atores e agentes sociais nas esferas de governo. Nessas repercussões deve ser incluída até mesmo uma certa perda de poder em termos de controle territorial ao legitimar a proliferação interna de territórios de segurança privada e a atuação de milícias (interna e externamente). Tanto uma forma como a outra podem servir ao Estado-Nação, a empresas privadas ou a seus próprios interesses, muitas vezes se apropriando de espaços públicos, como lembra Haesbaert (2011, p. 30-31).

Ao seguir, predominantemente, as colocações de Rogério Haesbaert a respeito do território como base para a discussão de gestão territorial, não se negligencia a contribuição de outros autores a esta temática.

O destaque será para Souza que, em diversas obras (1995 e 2013, por exemplo) apresentou significativas contribuições à importância do território no estudo das relações de poder. Para esse autor, território é "fundamentalmente, um espaço definido e delimitado por e a partir das relações de poder" (Souza, 1995, p. 78). Para que não se torne uma definição memorizável e vazia em si mesma, retoma essa reflexão em Souza (2013, p. 79) para discutir poder à luz de autores como Foucault, Arendt e Castoriadis e reafirma que, em seu ponto de vista, governo não é apenas governo estatal. Ainda segundo esse autor (p. 87) "também o poder só se exerce com referência a um território 
e, muito frequentemente, por meio de um território”. Podem ser vagos ou pouco perceptíveis, mas sempre haverá algum tipo de limites espaciais na concretização desse poder. Se se chama este autor para o debate é porque a ênfase que dá ao poder torna-se primordial em referências à gestão territorial como temática permanentemente "revolucionada" num espaço da metropolização, como o do estado do Rio de Janeiro, destacados os estudos que, há muito, desenvolve sobre a metrópole carioca.

Assim falar de gestão territorial deve implicar em lidar com múltiplos atores e agentes, múltiplas escalas de ação política e múltiplos papéis por eles representados. A seguir, sem maior aprofundamento, procuraremos apontar o movimento trilhado na execução das formas de planejamento e gestão territorial.

O planejamento foi pensado, há tempos, a partir de uma ótica tecnocrática. Do final do século XIX até, aproximadamente, 1940 foi possível identificar um plano, executado por sucessivos governos, de melhoramento e embelezamento das cidades.

Tendo em mente as duas maiores cidades do Brasil, no Rio de Janeiro o Plano Pereira Passos foi totalmente cumprido, já os Planos Agache (Rio) e Prestes Maia (São Paulo), em torno dos anos 1930, foram parcialmente cumpridos, mais especificamente apenas em suas propostas viárias. A partir de então, os problemas urbanos vão ganhando maior dimensão e a elite econômica já não é capaz de impor seus objetivos como anteriormente.

A questão habitacional cada vez mais se mostrava como problema fundamental. Foi durante o regime militar que a atividade de planejamento urbano mais se desenvolveu no Brasil, justamente com o lançamento do II PND (Plano Nacional e Desenvolvimento) no Governo Geisel, em 1973, SERFHAU - Serviço Federal de Habitação e Urbanismo e CNPU (Com. Nacional de Política Urbana, em 1974), por exemplo.

A atuação do BNH (Banco Nacional de Habitação), de 1964 a 1986, procurou trabalhar com dois grandes objetivos da política habitacional: alavancar o crescimento econômico através de efeitos multiplicadores gerados pela construção civil; e atender à demanda habitacional da população de baixa renda. Entretanto, apesar de ter havido um boom imobiliário, não contemplou a população de baixa renda. Pode-se observar o crescimento das favelas, dos loteamentos irregulares e de uma periferia em condições bastante precárias. 
Tal como se pode observar com o atual Programa Minha Casa Minha Vida, a especulação no que tange ao preço do solo urbano dificultou ainda mais o êxito dos programas habitacionais.

A partir de 1970, convive-se com o chamado "crescimento desordenado" e com a criação de programas alternativos que se baseavam na autoconstrução. Para dar conta do "caos urbano", o planejamento foi tomado como solução, entretanto, os planos foram criados por especialistas distantes e pouco engajados na realidade social do lugar. Segundo Maricato (2000), essas ideias dissimulavam os conflitos e os verdadeiros motores desse "caos".

Naquele período - e hoje não mudou muito - as obras de infraestrutura urbana alimentaram a especulação fundiária e não a democratização do acesso à terra, visando à moradia. Houve um maior controle nas áreas mais nobres da cidade, inclusive tendo havido políticas de remoção de favelas, mas nas áreas desvalorizadas para o mercado, a lei por vezes pôde ser transgredida. Assim, a gestão urbana juntamente com os investimentos públicos aprofundaram a concentração de renda e a desigualdade.

Os investimentos são feitos prioritariamente nas áreas nobres das cidades; nesse sentido, a cidade da elite definitivamente representa a cidade real (Maricato, 2000). Além de ocultar privilégios, isso possui um papel econômico ligado à geração da renda imobiliária.

No final da década de 1980, já livres do regime ditatorial militar, presenciou-se forte mobilização popular, que acabou por promover o encontro entre as organizações dos movimentos populares, partidos políticos, entidades profissionais, sindicatos, ONGs e pesquisadores universitários, o que posteriormente contribuiu para a construção do debate acerca da necessidade de uma reforma urbana.

Embora esse debate tenha sido intenso, resultou em apenas um capítulo com dois parágrafos em nossa nova constituição. Fato é que nos anos 2000 esse capítulo torna-se fortalecido pelo Estatuto da Cidade, que tem no Plano Diretor elemento fundamental.

Nos anos 1990, ainda sobre a recente onda de mobilização, duras críticas são feitas às formas anteriores de planejamento e gestão, inclusive muitos defendiam o fim do planejamento urbano e regional. Atacou-se o planejamento por ser rígido, burocrático, muitas vezes excessivamente ambicioso e incapaz de organizar verdadeiramente a estrutura urbana, já que o fazia privilegiando os interesses da elite. 
Alguns autores propõem o que denominaram "planejamento urbano alternativo", que, ancorado na possibilidade de participação popular na produção do Plano Diretor, poderia mudar a maneira de planejar a cidade. Evidentemente, a margem de manobra não era radical, pois falava na necessidade de priorizar a função social da propriedade e não em sua negação.

O planejamento urbano alternativo baseia-se na busca da justiça social, dessa maneira, preocupa-se com a melhor distribuição de investimentos públicos em infraestrutura, objetivando minimizar a segregação residencial. Mas a verdade é que da confecção da Nova Constituição Brasileira até a criação da lei que regulamenta os dois artigos acerca da reforma urbana (conhecida como Estatuto da Cidade) se passou muito tempo, algo em torno de 13 anos e isso acabou, de alguma forma, desmobilizando a população. Durante esse período, ganhou força uma forma de gestão que nega toda a lógica do planejamento urbano alternativo: o planejamento estratégico.

Através da elaboração de um Plano Estratégico, que tem origem na lógica empresarial e visa o lucro (e, nesse sentido, nada melhor do que convocar os empresários para fazê-lo) - as empresas têm planos estratégicos -, procura-se definir objetivos e políticas para conseguir acordos, coordenar às concessionárias privadas, dinamizar a economia e tornar as cidades competitivas em escala internacional. Contudo, essa lógica de planejamento e gestão não é facilmente desvelada, pois devido à propaganda e toda uma produção de city marketing, o que se faz em uma área restrita ganha ar de universal; ou seja, troca-se a parte pelo todo.

Planos como esses têm produzido mundo afora projetos, revitalizações e obras espetaculares que se espelham (muitas vezes são cópias fiéis) em "modelos de sucesso", o que tem produzido, como mencionamos anteriormente, mais do mesmo, ou seja, uma espécie de urbanização banalizada e mais do que isso, uma banalização do espaço (FERREIRA, 2013b).

É preciso, mais uma vez, pensar em novas formas de planejamento, baseadas no diálogo e na participação democrática, pois como diz Capel (2003, p. 241), "não podemos deixar que sejam os técnicos que nos dirijam, que nos ponham diante do fato consumado. Temos que impor o diálogo, tornar explícitas nossa opções e por os técnicos a nosso serviço". Aqui, embora não seja isso necessariamente o que Horacio Capel propõe, valeria a pena pensarmos na ideia de autogestão. 
Marx (2005), na busca da verdadeira democracia, acreditava que era necessário opor à burocracia a alternativa da autogestão, à autoridade do Estado a autonomia dos indivíduos. Evidentemente, chegar à verdadeira democracia, para Marx, significava caminhar para o desvanecimento do Estado (e nesse caso, necessariamente, para o fim do seu contraponto: a sociedade civil), o que levaria à constituição da comunidade.

Encaminhar-se-ia em direção a uma espécie de autogoverno, já que cada indivíduo governaria a si mesmo, assim a comunidade como um todo se autogovernaria. Haveria funções sociais e administrativas que continuariam a ser exercidas, mas não mais como funções estatais. Marx (2012) referir-se-ia a elas como funções sociais análogas àquelas do Estado, mas não idênticas (nem coercitivas ou opressoras), pois se tornariam funções públicas. Nesse sentido, em sendo funções públicas, as funções governamentais transformar-se-iam em funções administrativas. Para Marx, assim, a autoridade estatal cederia lugar à autonomia individual, já que a repartição das funções gerais transformarse-iam em algo tão rotineiro, que não confeririam qualquer autoridade.

A proposta de Marx, verdadeiramente, talvez até por não ter sido totalmente elaborada e instrumentalizada, nunca foi posta em prática, mas não nos resta dúvida que é bastante empolgante e inquietadora. Pensar que os cidadãos passam a ter várias atividades para vivenciar o ser político em plenitude (a ideia de preferir a expressão atividade à função também é bastante interessante), e também que a atividade dos homens à semelhança do que ocorre com a autodeterminação e o autogoverno (de si mesmo e, então, de todos) é que explica a autogestão é no mínimo um convite à ação. Com isso se alcançaria a possibilidade de conciliar as duas principais perspectivas na análise territorial: a mais funcional (que tem servido mais aos aparatos de controle) e a mais simbólica, que, se levada em consideração, oferece alternativas para formas de gestão mais democráticas e mais justas socialmente. As duas escalas - do espaço concebido e do espaço vivido - têm de ser conectadas em novas formas de (auto)gestão territorial, isto é, ligadas à vida no lugar.

\section{Metropolização do espaço e relações urbano-rurais: o lugar se impondo na matriz analítica}

Continuamos a embasar-nosna argumentação sobre a metropolização do espaço nas leituras que vêm sendo feitas dos trabalhos de Sandra Lencioni; para essa autora, 
esse processo de metropolização imprime ao território características que até então eram exclusivas da região metropolitana. Essas características fazem com que não só as práticas sociais, mas, inclusive as identidades dos lugares fiquem sujeitas aos códigos metropolitanos (LENCIONI, 2003, p. 35).

A partir dessa leitura, a ideia de metropolização corresponderia a uma organização espacialintegrada à lógica atual da acumulação capitalista na qual o espaço ganha uma dinâmica que ultrapassa a da aglomeração (complexos urbano-industriais, megalopolização), o que caracterizava a lógica fordista, na qual a tríade Estado, modelo político e o padrão técnico da produção exigiam fatores de localização que favoreciam tal aglomeração, preconizada, inclusive, nos modelos de planejamento vigentes na época, como foi evocado na segunda parte deste trabalho.

Entretanto, nas últimas décadas estabeleceu-se uma dinâmica em que se identifica uma espécie de desconcentração-concentrada, como desenho espacial, que poderia integrar-se à ideia de que a metrópole está em todos os lugares e ao mesmo tempo (SANTOS, 1993, p. 90), embora hierarquizando os subespaços, de acordo com o poder de decisão e da localização dos atores decisivos nesse processo de movimento do/no espaço.A interiorização ${ }^{\text {vii }}$ fluminense, em suas distintas faces(econômica, política, cultural) estaria integrada a essa desconcentração metropolitana que aqui é associada a estratégias do capital, as quais, através de seus atores hegemônicos (em conflitos mais evidentes ou mais velados com os agentes hegemonizados), desenvolvem ações que conformam o espaço, adequando-o a cada momento daquela acumulação, como já foi apresentado em Rua (2013, p. 81).

Continua-se a seguir as ideias de Milton Santos para quem tais ações estão relacionadas às intencionalidades que se percebem em um permanente processo de totalização, que faz com que os lugares, a cada movimento da sociedade, sejam recriados e renovados. O motor desse movimento e, portanto da diferenciação espacial, é a divisão do trabalho (técnica e social), responsável por cada lugar ser construído com um novo conteúdo e com um novo sentido, conforme Santos (1996).

Num primeiro ponto de construção da análise deve ser registrado que, ao mesmo tempo em que se notava a transformação da lógica espacial fordista para uma lógica pós-fordista (ou de acumulação flexível), na qual predominam a desconcentração e a localização dispersa (ou as expressões espaciais do desenvolvimento desigual e combinado?), notou-se, também, uma mudança dos enfoques analíticos. À lógica Geo UERJ. Rio de Janeiro - Ano 16, no. 25, v.2, $2^{\circ}$ semestre de 2014, pp.477-504 
anterior relacionavam-se os estudos de geografia agrária ou agrícola, procurando expressar a divisão de trabalho entre cidade e campo que nela vigorava. A cidade (sinônimo de urbano) era o lugar da indústria e dos serviços; o campo (sinônimo de rural) marcava-se pela agricultura, pecuária e extrativismo. Com algumas alterações esses recortes vigoram até hoje nas estatísticas oficiais brasileiras, ainda marcadas pela concepção de que rural é o que não é urbano - um resíduo fadado a desaparecer. Entretanto na medida em que as atividades econômicas e a vida cultural se descentralizam, integrando as escalas locais e globais, e alcançam as pequenas e médias cidades assim como os pequenos aglomerados rurais, num território tão marcado pelo processo de metropolização, como é o estado do Rio de Janeiro, as mudanças nos meios de subsistência das pessoas que aí vivem e de seus modos de vida, aceleram-se velozmente. Nessas localidades e até mesmo no rural disperso instalam-se fixos espaciais, antes característicos das (grandes) cidades e recebem fluxos de informações, capazes, uns e outros, de difundir os códigos urbano-metropolitanos que transformam o tempo e formas de trabalho e da vida. A essas formas materiais e imateriais vem se denominando urbanidades no rural ${ }^{\text {viii }}$, conforme Rua (2002, 2005, 2011, 2013), pretendendo-se com isso enfatizar a importância do fenômeno metropolitano como predominante na produção atual do espaço geográfico. Ao invés de se falar em novas ruralidades, como a maioria dos autores faz, prefere-se a ideia de urbanidades no rural como sintetizadora da hibridez entre rural e urbano, com predomínio deste, sem que o rural desapareça, ao contrário, revista-se de qualificações a partir da expansão do trabalho abstrato, antes apenas atribuídas às cidades, mas que agora, num espaço urbano-metropolitano alcançam todo o território fluminense, tomado como empiria para as pesquisas até agora realizadas. Tenta-se, com isso, ultrapassar a dicotomia obsoleta (LERNER e EAKIN, 2011) ao repensar-se as novas interfaces rural-urbanas como um mosaico de rurais e urbanos diversificados, manifestações do trabalho abstrato Ao mesmo tempo procura-se, ao enfatizar as interações e o hibridismo, um reforço aos estudos das relações urbano-rurais, nelas incluindo a necessária relevância das pesquisas sobre o ambiente natural e sua mercadificação, numa aproximação com as preocupações de Woods (2009). Tal reforço poderia instrumentalizar políticas de gestão territorial em que o lugar, no sentido relacional de Massey (2000 e 2008) em que a globalização refaz os espaços rurais, fosse tomado como instância constitutiva de formas de governança 
que minimizassem o modelo urbanocêntrico, plasmado na modernidade ocidental burguesa. É necessário desconstruir o conceito de urbanidade e o discurso que o relaciona apenas à cidade, na qual reside a cidadania. Para Ribeiro (1995) no Brasil haveria uma urbanização sem cidadania, e os projetos de desenvolvimento das cidades não seriam consistentes, apenas transformando-as em palcos para ações emergenciais e transitórias desarticuladas. Assim escreveu a autora, antecipando-se ao que viria a tornar-se norma nas metrópoles brasileiras:

Essa redução não contribui para a conquista coletiva de um nível deurbanidade, isto é, de amadurecimento das relações políticas e socioculturaisno urbano, compatível com o agudo grau de urbanização alcançado pelo paísnas últimas décadas. Ao contrário, talvez possamos dizer que é sobretudo naqualidade da vida urbana, em suas condições materiais e sociais, que maisclara e rapidamente pode ser apreendida a incongruência histórica do desenvolvimentobrasileiro, expresso num hibridismo entre formas e práticas sociaisreprodutoras de padrões internacionais de consumo e exclusões radicalizadas (RIBEIRO, 1995, p. 557).

A argumentação da autora reforça a ideia aqui defendida de que é preciso pensar em urbanidade com cidadania no urbano e no rural, numa busca de cidadania para todos.Para isso são necessários estudos que investiguem as maneiras como os lugares vivenciam a metropolização do espaço, já que é neles que, concretamente, ela se realiza. O conceito de metropolização do espaço é introduzido como expressão maior, em termos de escala, do lugar aberto a interações com o externo, portanto não xenófobo, à maneira de Massey (2000 e 2008).

Como já apresentado em Rua (2013, p. 82), retomando a ideia de metropolização, estamos de acordo com Massey (2008, p. 32) quando, ao discutir o espaço e a necessidade de considerá-lo aberto e produto de inter-relações, escreve que "nesse espaço aberto, interacional há sempre conexões ainda por serem feitas, justaposições ainda a desabrochar em interação... relações que podem ou não ser realizadas". O espaço da metropolização será esse espaço aberto, multiescalar, com interações a desabrochar, dinâmico, portanto, tendo como apoio uma grande metrópole que imprime seu ritmo a esse espaço, em negociação com os ritmos dos lugares.

A compreensãodessa nova geografia do rural integrado à escala geral da metropolização do espaço (em interações urbano-rurais) requer a necessidade de perceber como os lugares vão se refazendo num rural transformado, mas permanecendo rurais, só que resultantes das interações (sempre provisórias) agora vividas e 
negociadas. Essa negociação entre atores e agentes locais e extra-locais e de todos eles com o ambiente natural, implica em rupturas com o sistema de dominação e subordinação até agora vigentes, exige respeito às diferenças, com eliminação ou minimização das desigualdades sociais, num desafio aos padrões estabelecidos na modernidade ocidental e reconhecendo a autonomia local e regional.

Essa visão de rural integrado à lógica da metropolização do espaço é de difícil operacionalização pela sua alta subjetividade, quando comparado aos enfoques normativos, quantitativos e setoriais, estes rejeitando os aspectos específicos e simbólicos do rural. A abordagem territorial, com base em gestão localizada ${ }^{\mathrm{ix}}$, permitiria uma valorização dos conhecimentos dos habitantes dos lugares, incluindo as relações com o ambiente natural, além da organização espacial conduzida pela solidariedade, conforme preconizado por Santos (2000, p, 146) quando escreve que "na divisão de trabalho por baixo, o que se produz é uma solidariedade criada dentro e dependente de vetores horizontais cimentados no território e na cultura locais". Se se retornar às colocações de Massey antes referidas, percebe-se as complementaridades nos posicionamentos dos dois autores. Milton Santos, de há muito, chama atenção para as interações (assimétricas) entre o interno e o externo ao lugar; Doreen Massey, ao enfatizar as geometrias de poder (assimetrias?) fala de uma constelação particular de relações sociais, que se encontram e entrelaçam num lócusparticular, o interno e o externo interagindo assimetricamente.

É necessário estar atento para o paradoxo que se anuncia: de um lado preconiza-se a necessidade de ações políticas que se oponham à heteronomia vigente. O lugar vem emergindo como lócus preferencial da resistência (explícita ou latente), num movimento a que alguns chamam de uma espacialidade "radical" rural (HALFACREE, 2007) mesmo que potencial, diz o autor - quando se fala das relações urbano-rurais, colocadas como contraponto ao capitalismo urbanocêntrico. Movimentos de autonomia indicam a manutenção da resistência. Por outro lado não se pode deixar de relativizar a força de tais movimentos frente às assimetrias de poder entre a escala global e a do lugar. É necessário deixar evidentes os processos de acumulação primitiva (original) do capitalismo continuada hoje em dia, por outro lado, devem ser explicitadas as contradições desse processo e as "brechas" que nele se abrem para ações contrahegemônicas.

Geo UERJ. Rio de Janeiro - Ano 16, nº. 25, v.2, $2^{\circ}$ semestre de 2014, pp.477-504

ISSN: 1415-7543 E-ISSN: 1981-9021

http://www.e-publicacoes.uerj.br/index.php/geouerj 


\section{Considerações finais}

Contraditoriamente, o capitalismo que construiu a cidade como lócus do poder, cenário privilegiado da reprodução social, subordinada à indústria, fez com que ela implodisse sobre si mesma e explodisse sob a forma de tecido urbano e carregasse consigo o germe da polis e da civitas, como escreveu Monte-Mór (2006).

O trabalho que agora se apresenta, busca explicitar tal contradição ao demonstrar que "ao carregar consigo o germe da polis e da civitas" carregou (fazendo parte do processo) também a necessidade expansionista do capitalismo e as velhas e novas formas de acumulação primitiva, às quais Harvey (2004, p. 121) denomina acumulação por espoliação, na qual se destacam, hoje em dia, aquelas advindas de programas de revitalizações acompanhadas de gentrificação, a mercadificação do rural e do ambiente natural, privatização de áreas públicas (incluindo áreas protegidas, graças às mudanças de legislação - vide Código Florestal Brasileiro), a desproteção ao trabalhador, o sistema de crédito à disposição de governos de cidades, como se leu já neste trabalhoe o açambarcamento de terras (land grabbing) que, no mundo e no Brasil, vem se apresentando como uma das mais importantes formas de acumulação de capital. Não à maneira tradicional, historicamente reconhecida, mas como uma lógica financeira (urbana),que desafia os estudos sobre renda da terra.

Assim, ao que parece e concordando com Monte-Mór (2006, p.11), a práxis urbana, antes restrita à cidade, re-politizou todo o espaço social. Ao construir o conceito de urbanização extensiva.Relata o autor citado:

É neste sentido amplo que se pode falar de uma urbanização extensiva que se impõe no espaço brasileiro para muito além das cidades, integrando espaços rurais e regionais ao espaço urbano-industrialatravés da expansão da base material requerida pela sociedade e economia contemporâneas edas relações de produção que são (ou devem ser) reproduzidas pela própria produção do espaço (MONTE-MÓR, 2006, p. 12).

Mesmo corroborando essa abordagem, pensa-se que a urbanização extensiva não contempla, em termos de nomenclatura e de processo, as particularidades do rural, embora transformado, como já repetidamente visto, mas permanecendo como uma construção social específica. Pode dar ideia de um continuum, o que efetivamente não ocorre, já que não se trata de uma urbanização do rural, mas de uma urbanização no 
rural (RUA, 2002) - hoje, talvez se deva falar em metropolização no rural - o que conduz a pensar em continuidades (mesmo assim, não à maneira de uma mancha de óleo), mas, também, em rupturas e descontinuidades (RUA, 2011a). É necessárioresgatar as especificidades, presentes na ideia de urbanidades no rural, que aqui se utiliza. É nessa análise que se encontram o conceito de lugar, já bastante referido, o lugar rural, com a ideia de multiescalaridade que integra as leituras da metropolização do espaço (escala mais ampla) com as leituras específicas efetuadas no lugar, pelos agentes e atores em conflito/negociação que serão particulares. A metropolização do espaço se realiza no lugar.

Dentre as urbanidades no rural, anteriormente elencadas, escolheu-se o preço da terra para exemplificar as interações entre a metropolização do espaço, a gestão territorial e as relações urbano-rurais no lugar, seguindo as reflexões, a esse respeito, apresentadas em Rua (2011 e 2013).

Para sustentar as argumentações procurou-sea teoria do desenvolvimento desigual e combinado, na leitura que dela fez David Harvey (2004 e 2006) com os desenvolvimentos geograficamente desiguais. Escreve esse autor que

o exame do mundo em qualquer escala particular revela de imediato toda uma série de efeitos e processos que produzem diferenças geográficas nos modos de vida, nos padrões de vida, nos usos dos recursos, nas relações com o ambiente e nas formas políticas e culturais. A longa geografia histórica da ocupação humana da superfície da terra e da evolução distintiva de formas sociais (línguas, instituições políticas e valores e crenças religiosos) inseridas integradamente em lugares com qualidades todas suas tem produzido um extraordinário mosaico geográfico de ambientes e modos de vida socioecológicos (HARVEY, 2004, P. 110).

Essa citação serve para fixar que as diferenças geográficas, transformadas em desigualdades espaciais pelo capitalismo, são perpetuamente reproduzidas, sustentadas e reconfiguradas por meio de processos político-econômicos e socioecológicos, dentre eles a posse da terra, a renda que ela oferece e o preço de mercado que se obtém.

O preço da terra será compreendido como elemento de desigualização geográfica, na medida em que a terra vem sendo convertida em capital fictício em consonância com as novas formas de apropriação da renda por ela gerada. Isso se dá através da relação direta entre a esfera financeira e os investimentos em compra de terras para produção ou para especulação, movimento muito acentuado com a recente crise do capitalismo. Harvey (2004, p. 121), recorrendo a Marx, escreve que

Geo UERJ. Rio de Janeiro - Ano 16, no. 25, v.2, $2^{\circ}$ semestre de 2014, pp.477-504

ISSN: 1415-7543 E-ISSN: 1981-9021

http://www.e-publicacoes.uerj.br/index.php/geouerj 
um exame mais detido da descrição que Marx faz da acumulação primitiva revela uma ampla gama de processos. Estão aí a mercadificação e a privatização da terra e a expulsão violenta de populações camponesas; a conversão de várias formas de direitos de propriedade (comum, coletiva, do Estado etc.) em direitos exclusivos de propriedade privada; a supressão dos direitos dos camponeses às terras comuns [partilhadas]; a mercadificação da força de trabalho e a supressão de formas alternativas (autóctones) de produção e de consumo(HARVEY, 2004, P. 121)

O mesmo autor explicita novas formas de expropriação usadas pelo capitalismo contemporâneo como os direitos sobre a propriedade intelectual e as patentes, a escalada da destruição dos recursos naturais, a nova onda de expropriação de terras comuns, o papel do Estado dando legalidade a essa espoliação etc.

Aqui se apresenta, como reflexão, a ideia de que se para o capitalista parecia irracional fixar capital na compra de terras (imobilizado, não produtivo), atualmente, tal "irracionalidade" aparece bem relativizada. Há muitas indicações (internacionais e nacionais) de que o ativo financeiro terra atrai, crescentemente, os interesses especulativos.

Apresentam-se dois exemplos desse processo de land grabbing no Brasil e depois um no estado do Rio de Janeiro.

Discreta, Tiba Agro investe pesado na aquisição de terras
Carolina Mandl -Valor Econômico - Agronegócios - 15/03/2010
Um grupo pouco conhecido de produtores rurais e investidores financeiros criouuma empresa com
foco na aquisição de propriedades rurais, a Tiba Agro. À surdina,eles já têm em mãos 320 mil
hectares de terras no Cerrado brasileiro, montante quesupera o estoque acumulado por companhias
como BrasilAgro, Calyx Agro e SollusCapital.
O projeto surgiu de uma gestora de recursos, a Vision Brazil Investments, dedois ex-executivos do
Bank of America: Fabio Greco e Amauri Fonseca Junior, que têmfatia de $25 \%$ da Tiba.
Para juntar os recursos necessários para a aquisição das áreas, eles levantaramUS $\$ 300$ milhões por
meio de fundos de private equity, com cotistas americanos eeuropeus que passaram a ter $45 \%$ da
companhia. Também se uniram a dois produtoresrurais, os irmãos Francioni, da Bahia, e o grupo
Golin, da região Centro-Oeste, que jápossuíam algumas fazendas que foram trocadas por $30 \%$ da
Tiba.Agora, para dar corpo à nova companhia, todos os ativos, distribuídos emdiversos veículos de
investimento, estão sendo reunidos debaixo do guarda-chuva daTiba Agro.

Outro exemplo interessante de empresas que se envolvem com a compra de terras sem, por enquanto, se envolverem com a produção, é apresentado a seguir: 


\section{Valor Econômico - 15/03/2010 - (Segunda-feira). Carolina Mandl}

Um exemplo de companhia que compra terras com capital estrangeiro e brasileiro é a Sollus, que tem como sócios o Pactual Capital Partners (PCP), o grupo argentino Los Grobo e o fundo americano de commodities Touradji. Ela possui $35 \mathrm{mil}$ hectares de propriedades agrícolas e pretende encerrar o ano com 80 mil hectares, sem se envolver com a produção.

Também no estado do Rio de Janeiro esse processo de financeirização e açambarcamento (land grabbing) está presente, como se observanas grandes obras em realização (construção ou duplicação de rodovias, implantação de grandes plantas industriais e construção de portos), todas com enormes implicações sobre o ambiente natural e, sobretudo, sobre os meios de sobrevivência das pessoas. Toma-se como exemplo o Porto do Açu, no Norte Fluminense. A elevação do preço da terra, a grilagem, o uso da gestão territorial, na esfera estadual e municipal, são apenas algumas formas de viabilização da acumulação primitiva nos dias atuais (ou acumulação por espoliação, em Harvey),na qual se nota a ambiguidade dos processos de desenvolvimentos geograficamente desiguais, já que apenas intervenções localizadas, se fazem presentes. $\mathrm{O}$ necessário progresso e o desenvolvimento dos meios produtivos,obrigatoriamente, têm de acarretar a precarização das condições de vida das pessoas nos lugares? É claro que alternativas a esse processo devem existir. Entretanto, o que se percebe na realidade, com mais frequência, é a prevalência da racionalidade econômica, sobrepujando as necessidades sociais, como se demonstra, a seguir.

Desenvolvimento e Escalas de Conflito Ambiental: o caso do Complexo Logístico-Industrial do Porto do Açu em São João da Barra (RJ) Suyá QuintsIr (doutoranda do IPPUR)

Cadernos do Desenvolvimento Fluminense, Rio de Janeiro, n. 4, mai. 2014

Este artigo tem o objetivo de discutir o Complexo Logístico-Industrial do Porto do Açu (CLIPA) a partir de três eixos principais. Em primeiro lugar, enfoca o contexto de reposicionamento do Brasil na divisão internacional do trabalho como exportador de commodities primárias, que condicionou a aprovação, em 2013, de um novo marco regulatório com o objetivo de ampliação dos investimentos em infraestrutura portuária. Em segundo lugar, focaliza as alterações territoriais promovidas pela instalação do porto e os conflitos ambientais decorrentes de sua incompatibilidade com outros usos do território, em especial pesca artesanal e agricultura. Por fim, são avaliadas as características do empreendimento à luz da estrutura econômica e trajetória de ascensão e queda do grupo controlador, problematizando sua transferência a um fundo de investimentos estrangeiro. Nesse debate, o porto é compreendido como uma "janela" que unifica os três eixos, permitindo uma abordagem multiescalar centrada no Estado e no empreendedor, na intensificação dos conflitos envolvendo a apropriação dos recursos ambientais no território e no processo de acumulação por espoliação no Brasil contemporâneo. 
Retoma-se uma citação de Sandra Lencioni como demonstração da importância do preço da terra no processo de metropolização do espaço, já que

a dinâmica do processo de metropolização vai envolvendo áreas e modificando o mercado de terras, que passa, assim, por uma maior "valorização", ou seja, por um aumento de seu preço. Em outros termos, há uma elevação geral do preço da terra, pois a propriedade privada da terra se constitui numa condição indispensável à produção imobiliária formal, que (não exclusivamente) mercantiliza o espaço (LENCIONI, 2013, p. 26-27).

Em se tratando especificamente do rural, a elevação dos preços da terra está integrada à valorização de determinados vetores espaciais, que vêm sendo denominados "eixos de maior adensamento de urbanidades no rural", como se apresenta em Rua (2011, p. 94). Desses eixos, neste trabalho, destaca-se o eixo litorâneo norte, particularmente entre os municípios de Macaé e São João da Barra, onde mais se fazem presentes os efeitos da exploração petrolífera da Região Norte Fluminense. O Porto de Açu, nela se encontra.

Alguns exemplos de elevação do preço da terra, na região supracitada:

\begin{tabular}{|c|c|c|c|c|}
\hline \multicolumn{5}{|c|}{$\begin{array}{l}\text { Valor da Terra Nua Para Alguns Municípios da Região Norte Fluminenses. } \\
\qquad 2009-2014\end{array}$} \\
\hline $\begin{array}{l}\text { Municíp } \\
\text { ios }\end{array}$ & $\begin{array}{l}\text { \$/Hectare/2 } \\
009\end{array}$ & $\begin{array}{l}\text { \$/Hectare/2 } \\
011\end{array}$ & $\begin{array}{l}\text { \$/Hectare/2 } \\
012\end{array}$ & $\begin{array}{l}\text { \$/Hectare/2 } \\
014\end{array}$ \\
\hline $\begin{array}{c}\text { Campos } \\
\text { dos } \\
\text { Goytacazes }\end{array}$ & $2.000,00$ & $2.800,00$ & $2.985,00$ & 3150,00 \\
\hline $\begin{array}{l}\text { Carape } \\
\text { bus }\end{array}$ & $2.000,00$ & $2.335,00$ & $2.490,00$ & 2630,00 \\
\hline Macaé & $2.000,00$ & $2.335,00$ & $2.490,00$ & 2630,00 \\
\hline $\begin{array}{l}\text { Quissa } \\
\text { mã }\end{array}$ & $2.000,00$ & $2.800,00$ & $2.985,00$ & 3150,00 \\
\hline
\end{tabular}

Geo UERJ. Rio de Janeiro - Ano 16, no. 25, v.2, $2^{\circ}$ semestre de 2014, pp.477-504

ISSN: 1415-7543 E-ISSN: 1981-9021

http://www.e-publicacoes.uerj.br/index.php/geouerj 


\begin{tabular}{|c|c|c|c|c|}
\hline São & $\mathbf{2 . 0 0 0 , 0 0}$ & $\mathbf{2 . 8 0 0 , 0 0}$ & $\mathbf{2 . 9 8 5 , 0 0}$ & $\mathbf{3 1 5 0 , 0 0}$ \\
João da & & & & \\
Barra & & & & \\
\hline
\end{tabular}

Fonte: Diário Oficial do Estado do Rio de Janeiro de 07/08/2009, 24/07/2012,31/07/2013 e 06/08/2014.

Com todas as ressalvas que se possam fazer a esses dados (médias municipais, não levar em consideração a natureza dos distintos solos, dificuldades de conciliar distintos interesses entre técnicos, donos da terra e autoridades municipais e federais), ainda assim servem para demonstrar as dificuldades que, crescentemente, se opõem a quem as ocupa (particularmente aos ocupantes e aos pequenos proprietários) quando conflitos de interesses se instalam na escala do lugar. As já aludidas assimetrias de poder, aspectos sensíveis da metropolização do espaço e da gestão territorial, explicitam-se na figura dos atores hegemônicos (grandes incorporadoras e investidores - às vezes estrangeiros o Estado, em suas ações de controle "da ordem” e nas ações de driblagem da legislação) e dos agentes locais que se veem muitas vezes obrigados a deixar seu lugar, e que outras vezes resistem (fazendo-se atores da resistência), se organizando e contando com apoios externos ao lugar, para participar desse jogo de forças.

Notas

${ }^{\mathrm{i}}$ Indovina (1990), Capel $(2002,2003)$

${ }^{i i}$ Monclús (1998)

iii Lencioni (1996, 2006, 2013), Delgado (1998), Sambricio (1999), Téran (1999), dentre outros

${ }^{\text {iv }}$ Nel.lo (1998)

v Amplamente abordada por Sandra Lencioni na conferência de abertura do II Simpósio Internacional sobre Metropolização do Espaço, Gestão Territorial e Relações Urbano-Rurais

${ }^{v i}$ Corboz (1995)

vii Partilha-se a ideia de que ocorre uma certa desconcentração metropolitana de atividades produtivas e culturais em direção ao interior fluminense, embora com forte domínio da cidade do Rio de Janeiro e da sua Região Metropolitana, com relação ao interior, como já discutido em Rua (2007). Entretanto acreditase que essa interiorização não contém o tom otimista de "recuperação do interior frente à capital", como alguns autores anunciam. Para os autores deste artigo trata-se de um movimento coerente com a estratégia atual dos investimentos sendo realocados no espaço, naqueles locais onde as vantagens competitivas se anunciem. Essa crítica não invalida o destaque dado às intensas alterações sofridas por algumas áreas do interior (base da nossa argumentação). Só queremos enfatizar que se trata de um processo muito complexo que contém aspectos positivos e negativos em permanente interação, o que, pelo menos, relativizaria os tons otimistas por muitos utilizados. É preciso dar destaque à produção de petróleo como principal motor dessa interiorização e perceber que, ao mesmo tempo, ocorre a desconcentração acima aludida, mas ocorre, também, uma revitalização de algumas áreas do interior que interagem com o movimento oriundo da metrópole. Não se percebe o interior como inerte recebendo apenas "energia" da capital e sim como forte alimentador de tal energia

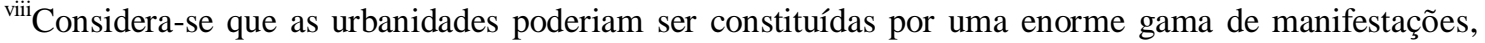
que incluiriam, em seus aspectos materiais, a melhoria da infraestrutura e dos meios de comunicação, novas formas de lazer, a segunda residência, as antenas parabólicas e o acesso à informação, o turismo, as indústrias em áreas rurais, o uso de bens de consumo coletivo, especulação imobiliária com novas

Geo UERJ. Rio de Janeiro - Ano 16, no . 25, v.2, $2^{\circ}$ semestre de 2014, pp.477-504

ISSN: 1415-7543 E-ISSN: 1981-9021

http://www.e-publicacoes.uerj.br/index.php/geouerj 
características e o preço da terra, novas relações de trabalho, direitos trabalhistas, aposentadoria rural, dentre outros indicadores a relevar. Como aspectos mais simbólicos poderiam ser citados os valores antes predominantes nas cidades, a moda e a estética de feição urbana, a preocupação com a segurança, os costumes e os hábitos difundidos pela mídia que alteram sobremaneira a vida cotidiana rural. No dizer de Lefebvre, (2001, p. 12) "uma racionalidade divulgada pela cidade". Não há uma conotação valorativa (positiva ou negativa) de tais urbanidades já que são apenas evidências de um processo geral de integração do espaço que é marcado pelas relações de poder que caracterizam o momento atual de organização da sociedade, com seus conflitos e cooptações.

ix Harvey (2013, p. 479) considera que "a localização é socialmente construída, se constituindo um atributo material fundamental para o homem"

\section{Referências}

ALVES, Giovanni. Trabalho, subjetividade e capitalismo manipulatório - o novo metabolismo social do trabalho e a precarização do homem que trabalha. Estudos do Trabalho, Ano V, Número 8, Marília, UNESP, 2011.

CAPEL, Horacio. La Cosmópolis y la ciudad. Barcelona: del Serbal, 2003. 248p.

CAPEL, Horacio. La morfología de las ciudades: sociedade, cultura y paisage urbano. Barcelona: del Serbal, 2002.

CORBOZ, André. L’ipercittá. Urbanistica. n.103, 1995.

FERREIRA, Alvaro. Metropolização do espaço, tensões e resistências: entre espaços de controle e controle do espaço. Scripta Nova: Revista Electrónica de Geografía y Ciencias Sociales, Vol. XVIII, núm. 493 (55), 1 de noviembre de 2014, Universidad de Barcelona.

FERREIRA, Alvaro. A imagem virtual transformada em paisagem e o desejo de esconder as tensões no espaço: por que falar em atores, agentes e mobilizações? In FERREIRA, Alvaro, RUA, João, MARAFON, Glaucio, SILVA, Augusto César Pinheiro da (org.) Metropolização do espaço: gestão territorial e relações urbano-rurais. Rio de Janeiro: Consequência, 2013a. p. 5374.

FERREIRA, Alvaro. A cidade no século XXI: segregação e banalização do espaço. 2 ed. Rio de Janeiro: Consequência, 2013b.

FERREIRA, Alvaro. O processo de metropolização do espaço no Estado do Rio de Janeiro e os projetos de revitalizações: mais do mesmo? GeoPuc (Rio de Janeiro), v. 4, p. 17-52, 2011.

HAESBAERT, Rogério. O mito da desterritorialização: do "fim dos territórios" à multiterritorialidade. Rio de Janeiro: Bertrand Brasil, 2004.

HAESBAERT, Rogério. Da desterritorialização à multiterritorialidade. Anais do IX Encontro Nacional da ANPUR. Ética, Planejamento e Construção democrática do espaço. Rio de Janeiro 28 de maio a 1 de junho de 2001. Vol. III, p. 1775-1783. 2001.

HAESBAERT, Rogério. Da Desterritorialização à Multiterritorialidade. Anais do X Encontro de Geógrafos da América Latina. Departamento de Geografia, 20-26 de março de 2005. USP.

HAESBAERT, Rogério. Des-territorialização e identidade a rede "gaúcha" no Nordeste. Niterói: EDUFF, 1997.

HAESBAERT, Rogério. Território e Multiterritorialidade - um debate. GEOgraphya - Revista de Pós-graduação em Geografia da UFF.Niterói/RJ: UFF/EGG, Ano IX, n. 17, p. 19-46, junho de 2007. 
HALFACREE, Keith. Trial by space for a 'radical rural': Introducing alternative localities, representations and lives. Journal of Rural Studies, 23, 2007, pp.125-141.

HARVEY, David. Justice, Nature and the Geography of Difference. Oxford: Blackwell, 1996.

HARVEY, David. Spaces of Global Capitalism. UK/USA: VERSO, 2006.

HARVEY, David. Os limites do capital. São Paulo: Boitempo, 2013.

INDOVINA, Franco. La cittá difusa. Veneza: Daest, 1990.

LEFEBVRE, Henri. O direito à cidade. Tradução de. Rubens Eduardo Frias. São Paulo: Centauro, 2001.

LENCIONI, Sandra. Metropolização do espaço: processos e dinâmicas. In FERREIRA, A. RUA, J. MARAFON, G. SILVA, A. C. P. da (orgs.) Metropolização do espaço: gestão territorial e relações urbano-rurais. Rio de Janeiro: Consequência, 2013. p. 17-34.

LENCIONI, Sandra. Reconhecendo metrópoles: sociedade e território. In SILVA, Catia Antonia da et al. Metrópole: governo, sociedade e território. Rio de Janeiro: DP\&A, 2006.

LENCIONI, Sandra. Uma Nova Determinação do Urbano: o desenvolvimento do processo de metropolização do espaço. In: CARLOS, A. F. A. e LEMOS, A. I. G. (orgs.) Dilemas Urbanos: novas abordagens sobre a cidade. São Paulo: Contexto. 2003b.

LENCIONI, Sandra. A emergência de um novo fato urbano de caráter metropolitano em São Paulo. A particularidade de seu conteúdo sócio-espacial, seus limites regionais e sua interpretação teórica. In Anais do X Encontro Nacional da ANPUR, Belo Horizonte, 2003a, CD-Rom.

LENCIONI, Sandra. Região e Geografia. São Paulo: Edusp, 1999.

LENCIONI, Sandra. Reestruturação urbano-industrial no estado de São Paulo: a região da metrópole desconcentrada. In SANTOS, M. SOUZA, M. A. de, SILVEIRA, M. L. (orgs.) Território: globalização e fragmentação. São Paulo: Hucitec, 1994, p. 54-61.

LENCIONI, Sandra. Reestruturação urbano-industrial: centralização do capital e desconcentração da metrópole de São Paulo. 1991. 286 f. Tese (Doutorado em Geografia Humana) - Faculdade de Filosofia, Letras e Ciências Humanas (FFLCH), Universidade de São Paulo, 1991.

LERNER, Amy M; EAKIN, Hallie. An obsolete dichotomy? Rethinking the rural-urban interface in terms of food security and production in the global south. The Geographical Journal. Volume 177, Issue 4, pages 311-320, December 2011

MARICATO, Ermínia. As idéias fora do lugar e o lugar fora das idéias: planejamento urbano no Brasil. In ARANTES, O. VAINER, C. MARICATO, E. A cidade do pensamento único: desmanchando consensos. Petrópolis, RJ: Vozes, 2000, p. 121-188.

MARX, Karl. Crítica da filosofia do direito de Hegel. São Paulo: Boitempo, 2005.

MARX, Karl. Crítica do programa de Gotta. São Paulo: Boitempo, 2012.

MASSEY, Doreen. Pelo Espaço: uma nova política da espacialidade. Rio de Janeiro: Bertrand Brasil. 2008.

MASSEY, Doreen. O sentido global do lugar. In ARANTES, A. A. (Org.). O espaço da diferença. Campinas: Papirus, 2000.

MÉSZARÓS, István. Para além do capital. São Paulo: Boitempo, 2002.

Geo UERJ. Rio de Janeiro - Ano 16, no . 25, v.2, $2^{\text {o }}$ semestre de 2014, pp.477-504

ISSN: 1415-7543 E-ISSN: 1981-9021

http://www.e-publicacoes.uerj.br/index.php/geouerj 
MONCLÚS, Francisco Javier. Estrategias urbanísticas y crecimiento suburbano em las ciudades españolas: em caso de Barcelona. In MONCLÚS, F. J. (orgs.). La ciudad dispersa. Barcelona: Centro de Cultura Contemporànea de Barcelona, 1998.

MONTE-MÓR, Roberto Luís de Melo. O que é o urbano, no mundo contemporâneo. Belo Horizonte: UFMG/Cedeplar, 2006.

NEL.LO, Oriol. Los confines de la ciudad sin confines: estrutura urbana y límites administrativos em la ciudad difusa. In MONCLÚS, F. J. (org.). La ciudad dispersa. Barcelona: Centro de Cultura Contemporànea de Barcelona, 1998.

RIBEIRO, Ana Clara Torres. Urbanização Sem Urbanidade: um cenário de incertezas. Ensaios Fee, Porto Alegre (16)2: 556-590, 1995.

RUA, João. O urbano no rural fluminense e o preço da terra: continuando a reflexão. In FERREIRA, A. RUA, J. MARAFON, G. SILVA, A. C. P. da (orgs.) Metropolização do espaço: gestão territorial e relações urbano-rurais. Rio de Janeiro: Consequência, 2013. p. 383-408.

RUA, João. A Complexa Simultaneidade da Integração e Distinção entre o Urbano e o Rural: Retomando um Debate no Espaço de Metropolização do Estado do Rio de Janeiro. Rio de Janeiro: GeoPUC Revista do Departamento de Geografia da PUC-Rio, ano 4, n. 7, segundo semestre de 2011. 2011b.

RUA, João. Continuidade ou Ruptura na Expansão da Metrópole para além de seus Limites Formais: urbanidades no rural? In: RANDOLPH, R. e SOUTHERN, B. (orgs.). Expansão metropolitana e transformações das interfaces entre cidade, campo e região na América Latina. São Paulo: Max Limonad. 2011a, pp. 186-201.

RUA, João. As crises vividas pelo estado do Rio de Janeiro e a emergência de novas territorialidades em áreas rurais. In: MARAFON, G. J. RUA, J. RIBEIRO, M. A. Abordagens teórico-metodológicas em Geografia Agrária (orgs.). rio de Janeiro: EdUERJ. 2007.

RUA, João. Urbanidades no rural: o devir de novas territorialidades. Campo - território. Revista de Geografia Agrária, 2006, v. 1, n. 1.

RUA, João A ressignificação do rural e as relações cidade-campo: uma contribuição geográfica. Revista da Anpege, Fortaleza, 2005, ano 2, n. 2, pp. 45-66.

RUA, João. Urbanidades e novas ruralidades no estado do Rio de Janeiro: algumas considerações teóricas. In MARAFON, G. J. e RIBEIRO, M. F. (orgs.). Estudos de geografia fluminense. Rio de Janeiro: Infobook, 2002b, pp. 43-70.

RUA, João. Urbanidades e Novas Ruralidades no Estado do Rio de Janeiro: Algumas Considerações Teóricas. In: MARAFON, G. J. RIBEIRO, M. F. (Orgs.). Estudos de geografia fluminense. Rio de Janeiro: Livraria e Editora Infobook, 2002a. p. 27-42.

SANTOS, Milton. A Natureza do Espaço: técnica e tempo, razão e emoção. São Paulo: HUCITEC. 1996.

SANTOS, M. Por uma outra globalização: do pensamento único à consciência universal.Rio de Janeiro: Record, 2000.

TÉRAN TROYANO, Fernando de. Madrid, Ciudad-Región. Vol. II. Entre la ciudad y el territorio en la segunda mitad del siglo XX. Madrid: Madrid, 1999.

WOODS, Michael. Rural Geography III: Rural futures and the future of rural geography. Progress in Human Geography, ano 36, n. 1, Londres, Sage Publications, 2012, p. 125-134.

WOODS, Michael. Rural Geography: blurring boundaries and making connections. Progress in Human Geography, ano 33, n. 6. Londres, Sage Publications, 2009, p. 849-858.

Geo UERJ. Rio de Janeiro - Ano 16, ${ }^{\circ}$. 25, v.2, $2^{\circ}$ semestre de 2014, pp.477-504

ISSN: 1415-7543 E-ISSN: 1981-9021

http://www.e-publicacoes.uerj.br/index.php/geouerj 
WOODS, Michael. Engaging the global countryside: globalization, hybridity and the reconstitution of rural place. Progress in Human Geography 31(4), Londres, Sage Publications, 2007, pp. 485-507.

WOODS, Michael. Rural Geography: processes, responses and experiences in rural restructuring. London: Sage Publications, 2005.

VAINER, Carlos B. Pátria, empresa e mercadoria: notas sobre a estratégia discursiva do Planejamento Estratégico Urbano. In ARANTES, O. VAINER, C. MARICATO, E. A cidade do pensamento único: desmanchando consensos. Petrópolis: Vozes, 2000.

Artigo recebido para publicação em outubro de 2014.

Artigo aceito para publicação em dezembro de 2014.

Geo UERJ. Rio de Janeiro - Ano 16, ${ }^{\circ}$. 25, v.2, $2^{\circ}$ semestre de 2014, pp.477-504

ISSN: 1415-7543 E-ISSN: 1981-9021

http://www.e-publicacoes.uerj.br/index.php/geouerj 